Du texte à la scène : langages du théâtre

\title{
In Memoriam (Jean Jacquot)
}

\section{Marie-Thérèse Jones-Davies}

\section{Q OpenEdition \\ Journals}

\section{Édition électronique}

URL : http://journals.openedition.org/shakespeare/1160

DOI : 10.4000/shakespeare.1160

ISSN : 2271-6424

Éditeur

Société Française Shakespeare

Édition imprimée

Date de publication : 1 novembre 1983

Pagination : 7-8

\section{Référence électronique}

Marie-Thérèse Jones-Davies, «In Memoriam (Jean Jacquot) », Actes des congrès de la Société française Shakespeare [En ligne], 4 | 1983, mis en ligne le 01 janvier 2007, consulté le 02 mai 2019. URL : http://journals.openedition.org/shakespeare/1160; DOI : 10.4000/shakespeare.1160 
SOCIETE FRANÇAISE SHAKESPEARE

Actes du Congrès 1982

\section{DU TEXTE A LA SCENE : Langages du Théâtre}

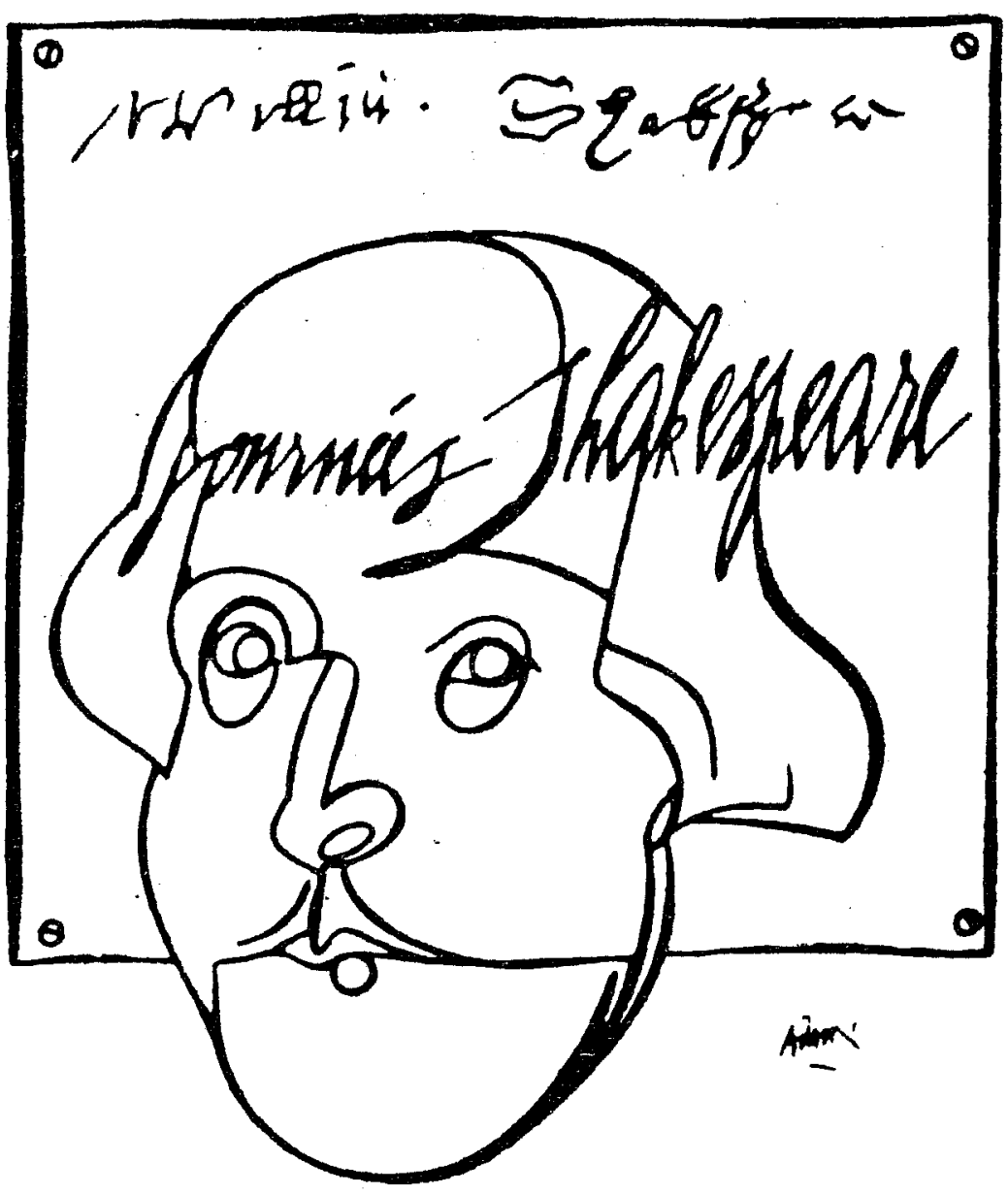

DiRecteur de la publication M.T. Jones - Davies

Publié avec le concours du Centre National de la Recherche Scientifique

JEAN TOUZOT Libraire - Editeur

38 , rue Saint-Sulpice 75278 PARIS CEDEX 061983 


\section{IN MEMORIAM}

«... les personnages de Shakespeare ne nous lâchent pas. On ne peut dire le dernier mot sur eux et passer à autre chose».

Cette remarque de Jean Jacquot dans son Shakespeare en France (Paris, 1964, p. 137) met en évidence l'intérêt majeur et constant qu'il devait porter lui-même pendant toute sa carrière à l'oeuvre du poète de Stratford.

Pourtant Jean Jacquot, qui avait soutenu une thèse de doctorat d'Etat sur George Chapman ne consacra pas seulement son temps à la littérature élisabéthaine. Successivement chercheur, maître, puis directeur de recherches au C.N.R.S., où il entra dès les années 50 , il eut le goût des travaux pluridisciplinaires, et il devint ainsi l'un des spécialistes de la Renaissance. Grâce à son érudition et à son insatiable curiosité intellectuelle, il sut imprimer leur caractère original aux divers colloques internationaux qu'il organisa et aux équipes qu'il anima. La Collection du C.N.R.S., Le Choeur des Muses, fondée par lui et publiée sous sa direction, révèle les multiples aspects de son savoir : musique, musicologie et luthistes français, théâtre, réalisme et poésie au théâtre, tragédies de Sénèque et théâtre de la Renaissance, types de lieu théâtral et leurs transformations, fêtes et spectacles ..., ou encore, avec la série intitulée Les Voies de la Création théâtrale, études sur les mises en scène de pièces modernes aussi bien que textes du passé, comme Le Juif de Malte ou Le Roi Lear.

Déjà en 1963, l'exposition dont il fut responsable, La Vie théatrale au temps de la Renaissance, montrait l'ampleur de ses recherches. Lethéâtre élisabéthain, qui «atteint son apogée ... au moment où l'on joue les oeuvres de Shakespeare», y avait une bonne place entre celui de l'Espagne et celui des Rederijkers. Cette exposition soulignait l'importance du rapport entre acteurs et spectateurs, des conditions de jeu et de leur incidence sur les représen- 
tations shakespeariennes.

Précisément, dès son origine, la Société Française Shakespeare voulut établir des liens entre les universitaires et le monde du théâtre, et examiner les relations du texte avec la scène. Par son expérience de toutes ces questions Jean Jacquot allait être l'un des fondateurs les plus appréciés de notre Société. Nous lui devons une infinie gratitude pour le rôle de premier plan, actif et efficace, que depuis 1978 , il assuma avec beaucoup de science et de tact. I1 participa à l'élaboration de tous nos programmes et facilita de nombreux échanges avec des metteurs en scène et des acteurs. Il rassembla les communications de nos Journées Shakespeare en 1979 et en prépara le compte rendu; il suscita et dirigea une Table Ronde sur Christopher Marlowe en 1981; et si, pour des raisons de santé, il ne put assister en personne au Congrès de 1982, il y fut cependant présent par ses conseils et ses encouragements, et contribua à la révision des textes de ce volume 1983.

Jean Jacquot resta en effet jusqu'au bout attentif à tout ce qui se disait et se pensait à propos des Elisabéthains et en particulier de Shakespeare et de ses personnages - tant il croyait toujours qu' «on ne peut dire le dernier mot sur eux et passer à autre chose».

C'est avec émotion que nous dédions cet ouvrages à la mémoire de ce grand ami de Shakespeare, qui fut aussi le nôtre.

A Madame Jacquot, la Société adresse sa profonde sympathie, et personnellement je tiens à exprimer le souvenir ému que je garde de plusieurs entretiens chaleureusement amicaux que j'eus avec eux deux, avenue de Choisy. Jean Jacquot savait allier à sa haute compétence ses grandes qualités humaines.

M.T. Jones-Davies 